\title{
Meaning and Structure in the Work and Family Interface
}

\author{
by Stefano Ba' \\ University of Huddersfield \\ Sociological Research Online, 15 (3) 10 \\ $<$ http://unw. socresonline.org.uk/15/3/10.htm/> \\ $10.5153 /$ sro. 2132
}

Received: 24 Mar 2009 Accepted: 11 Jun 2010 Published: 31 Aug 2010

\begin{abstract}
This article explores the work and family life of dual-earner parents, how they manage these commitments and how they respond to competing demands on their daily life. The analysis of qualitative data suggests that parents manage the work-family boundaries according to the specific meaning that they attach to these spheres of daily life, but it also points to employment structures informing parents' 'focus' on work and family and equally shaping these boundaries. Hence, this article assesses the relevance of these boundaries and how families mediate work and home. This mediating position is analysed through an approach whereby social and economic constraints become parameters informing parents' sense of self and the meanings used in the work and home articulation. Then, the symbolic side of the work-family interface becomes crucial to understand issues concerning the meaningful order of daily life and the emotional attachments of families to these domains. On this point, I argue that mechanistic approaches to the work-family articulation that take in consideration solely chronometric parameters cannot explore these issues as deeply. This article then advocates a qualitative approach to the work-family interface in order to understand better its cultural co-ordinates and contexts.
\end{abstract}

\section{Keywords: Work-Family Interface, Dual-Earner Parents, Symbolic Meaning, Work Constraints and Resources}

\section{Introduction}

1.1 Through the analysis of qualitative data, this research finds that parents talk about meaningful time for family and distinct time for work in a way that marks the relevance of different symbolic spheres. The ways they use work structures and resources suggest that work and family are not just institutionally defined domains (Lewis, 2001 and 2003; Gambles et al. 2006; Rossi, 2006; Nippert-Eng, 1996) and that parents are in the process of re-drawing the boundaries between these two spheres. Does this indicate a shift from work and family as institutionally defined structures to areas of (more individualised) meaning?

1.2 In his book on family connections, Morgan (1996) contends that questions around the boundary between work and family are vital for parents' daily life. There he asks: 'what do household members define as work or non-work? How do they draw the boundaries (...) in terms of everyday strategies?' and how do they devise strategies 'to resist work demands or to set up demarcations between work and non-work?' (1996: 39) and these questions have a precise function in the program of research outlined in his book. If the theoretical focus shifts from the concept of family to 'family practices', it is then important to understand what family is for its members, and what they understand as non-family practices. Hence this article explores how families experience what for them is qualitatively family time, and in comparison with that, what for them is work time and what kind of boundaries (if any) they manage between the two. I will do this by examining the sets of practices and tasks working parents associate with work and home and how experiences, bonds, and emotional foci are developed in relation to each other.

1.3 The majority of studies on the ways parents reconcile employment and family life are based on the assumption that work and family are solely spheres in competition for scarce resources, such as time and energy (Hochschild, 2003). This body of literature assumes that there is ' $x$ ' amount of time for work or family and ' $y$ ' amount of energy for work or family in a reciprocally exclusive way. However, this representation is here considered reductive in the light of a series of factors such as routines, rituals, and how people define themselves as parents and workers, that makes the work and family interface a complex set of interdependent aspects of life. So, this research explores how symbolically, in terms of an emphasis on meanings, working parents come to describe their life. Thus, instead of considering individuals as 'economic' agents geared to maximising time/energy use in both spheres (assumptions still dominant in 
studies such as: Berg et al., 2003; Goldsmith, 1989; Gottlieb et al. 1998; Halpern and Murphy, 2005; Peper et al., 2005), the perspective proposed in this article points at individuals that are economically motivated, but deeply influenced in their actions by symbolical and emotional factors (Brannen, 2005; Gatrell, 2005; Hochschild, 1997, 2003). Therefore, the emotional attachment that parents tend to develop for family - or work - life, and its relevance for the individual sense of self, is taken as central for this analysis (Lewis 2003; Nippert-Eng 1996; Rossi, 2006; Thompson and Bunderson, 2001).

1.4 Parents' experience of work and family life is related to the understanding of the symbolic attachments which they invest in these domains of daily life, rather than simply and solely the chronometric aspect of $x$ hours for work and $y$ hours for family. This symbolic relevance of the domains of daily experience is inferred by the type of emphasis on meaning (whether in the positive or negative) that parents refer to in their accounts, when they talk about family life and work time. An approach that considers symbolic and cultural elements is still not prevalent in the majority of studies on the work-family articulation. Parents' accounts point at a symbolic management of these spheres, in the sense that parents take into account, or try to, what is meaningful in 'family' and in 'work' when allocating time for these domains of daily life. The symbolic side of the work-family articulation allows to detect the link between meaning and structure, in the sense that what is meaningful for parents is related to their mediation of employment's constraints, and in their turn employment structures come to represent symbolic resources for parents. In the literature, this interplay of meaning and structure is rarely considered in its complexity.

1.5 Employment structures still shape the ways parents manage their life between work and family, but work, as well as constraints, represents a type of resource: indeed work for some of the parents represent a source of identity (Gambles et al. 2006; Lewis and Cooper, 2005; Wajcman and Martin, 2002). The ambivalence of work as symbolic resource and work as structural constraint makes difficult a straightforward reading of the work-family interface as un-problematic relation of value-neutrals quanta of time (Thompson and Bunderson 2001). In this article then the concept of work and family boundary indicates how working parents' mediation of work and family is linked to their vital sense of practical and symbolic order. On this point, I argue that mechanistic approaches to the work-family balance that take into consideration solely chronometric parameters (e.g. Vander Lippe, 2007) cannot explore these issues as deeply.

1.6 In this introduction I have used key concepts such as 'family', 'daily life' and 'symbolic', which need clarification before I use them again in the rest of the article. This research is interested in how parents manage their work life in conjunction with their home life and so for family is understood a childrearing unit composed of partners living with their offspring. With this definition I did not want to exclude from the analysis other forms of family (childless couples, single parents etc.), but for methodological reasons, which are also explained in the method section, I considered that the study of the work-family articulation would benefit from focussing on the dual-earner couple with young children. Moreover, with the term family, I wanted to stay close to participants' own definition of themselves: all of them defined themselves as families.

1.7 The term 'daily life' is understood to be what for participants their normal practices are and what for them a cyclical event is. The methodological focus on daily life is also dictated by an epistemological interest in the communicative side of life trajectories, which contain the possible meaning of social events

(Brunkhorst, 1996). The focus on everyday life then serves as a framework to understand the link between subjective meaning and social constraints (Morgan, 1996), and how social structures (like employment or household) come to gain a symbolic relevance for people.

1.8 With 'symbolic' I introduce a distinction between levels or kinds of meanings. I assume that there is a gap between the superficial statement of action and its underlying meaning. So to understand narratives about an event as symbolic, is to distinguish that specific narrative of an event as having other than a common meaning - usually of means and ends. In this article then I use the term symbolic whenever participants to this research are referring to meanings that go beyond the description of an activity ${ }^{[1]}$. The distinction is between manifest meanings that are immediately apparent and latent meaning, not immediately apparent but perceptible, in terms of their relative emphasis in participants' accounts (Gusfield and Michalowicz, 1984).

\section{Work and family as symbolic spheres}

2.1 The symbolic side of the work-family boundary - although never explicitly discussed - is a theme that keeps emerging in the Sociology of Family (Brannen, 2005; Brannen et al., 2002; Gatrell, 2005; Hochschild, 1997; Lewis, 2001, 2003; Nippert-Eng, 1996; Rossi, 2006) alongside the criticism of the 'mechanistic' approach that regards work and family as reified entities (Gatrell, 2005: 150). In that sense, Hochschild's studies (Hochschild 1996, 1997 and 2003) represent a benchmark for considerations on the symbolic side of the work-family interface: in such a perspective, the spheres of work and family are 
understood as 'enmeshed yet competing emotional cultures' (1997: xx). It is through the concept of emotional culture that symbolic factors inform the study of the work-family articulation, but these phenomena are not yet seen as embedded in the social contingencies of working parents, as they are in this study.

2.2 On that, it is important to take in consideration the recent publications by Gambles et al. (2006), Gatrell (2005), Donati and Prandini (2007), Lewis et al. (2009) and others (Richardson, 2006; Rossi, 2006; Smart, 2007) where new categories for the study of family and interpersonal life (and its relationship with work) are considered and where they propose approaches very relevant for this study. One approach prioritises the 'imaginary' of interpersonal life, that is, the importance of un-formal cultural elements and the utilisation of emotional resources in the analysis of family life (e.g. Richardson, 2006; Smart, 2007; Wajcman and Martin, 2002). By building on these studies and by considering emotions and the cultural elements framing these, my research addresses the surplus of meaning that working parents invest in family or work life and so the symbolic side of their experience, which represents a relatively new approach to these issues. Another approach emphasises the relational contexts of the family - that is, the relations within the family and between the family and its economic and social environment (Donati and Prandini, 2007). Within this approach the symbolic relevance of a relationship is taken as a sign of the type of connections that can be routinely established between the members of the family and their social contingencies (Rossi, 2006). In this study then, it is taken into consideration how the emotional involvement in this web of relations can transform the quality of these relations and so contributing to create new configurations of meaning, which to an extent has been theorised elsewhere (Thompson and Bunderson, 2001), but never articulated in an empirical research.

2.3 The empirically grounded concept of the symbolic side of family and work, devised for this research, has a resonance with some of the new categories emerging in Family Studies. A number of scholars have devised key concepts that are vital in understanding the constitution of interpersonal lives, such as the 'the realm of the imagined' (Smart, 2007: 34). Or they have called attention to renewed forms of rituals for family as well as for work life (Campbell-Clark, 2000; Nippert-Eng, 1996; Richardson, 2006). However, 'the symbolic' in this research has a double function: it focuses the sociological analysis on practices, but recognises also the excess of meaning people may invest in these. Developing such an insight, this article adds the novelty of pushing Morgan's concept of family practice to another level, a level that incorporates the immaterial side of what people do: their personal and cultural representations. By recognising that symbolic factors are constitutive of people's lives, this research makes a relational link between the structures where these symbolic attachments are developed and the subjective experience that people have of them, so providing a detailed description of what is socially significant.

2.4 Consistent with recent scholarship in this area, my approach is then orientated to 'encompass human interaction, meaning creation and complexity of work and home situation' (Campbell-Clark, 2000: 750) in the study of the work-family interface, looking for a systemic level of changes (Gambles et al. 2006), besides other factors such as time, energy and psychological 'spill-over' (Bailyn, 1993; Piotrkowsky, 1977). For instance, Voydanoff's (1987) or Vander Lippe's (2007) analysis in terms of role strains rests on assumptions about the mechanical relation of time and energy available for one role or the other, but the logical consequence of this approach turns conflicts and tensions into possible rational allocations of time to be made on the part of actors, therefore defusing this issue from all the conflicts experienced by families. Indeed, all the 'mechanisms for coordinating multiple roles over the work-family' interface analysed within this approach (e.g. Voydanoff, 1987, 2001) are abstract, reflecting the difficulties within this theoretical framework of making sense of the articulation of work and family in the social lives of parents, as these domains are assumed to be unproblematic entities. This type of analysis tend to confirm already known phenomena, such as 'young children increase time pressure for both men and women' (Vander Lippe, 2007: 705) or interpreting work deadlines as indicators of increase feelings of time pressure (704).

2.5 The aim of the present study is then to advance the research on the work-family boundary and to develop a deeper approach to the understanding of the symbolic side of the work-family interface. In particular the study of the symbolic side of the work-family boundary shows how a link is established between meaning and structure, how parents mediate what is meaningful for them with household and employment structures and in their turn how these structures come to represent material and symbolic resources/ constraints. The consideration of the symbolic factors in the investigation of the work-family interface answers the call for a 're-conceptualisation' (White et al., 2003: 191) of the nature of such issues.

\section{Method}

3.1 The qualitative findings reported in this article are part of a research conducted to explore the complex articulation of work and family life, focusing on the practices that parents perform in managing these domains of daily life and on the symbolic elements emerging in their accounts of work and home life. In order to explore the meanings, the practices and the emotional aspects implicated in the lives of working 
3.2 The sample consists of married/cohabiting couples living in and around Manchester (UK), where both partners are employed (either full- or part-time) and there is at least one dependant child (the ages of the children mainly falling in the range from 0 to 11 years). The dual-earner couple was chosen as it represents a meaningful context of work-family tension, and also because the dual-earner household is now the dominant form among those of working age; moreover the rate of increase in dual-earning households with dependant children has been very noticeable during recent years (Crompton, 2006).

3.3 Thirty-two families were recruited for this research, although in four cases I could obtain interviews with only one member (the woman in each case). Parents of young children both of whom have paid employment commitments are the type of people who necessarily cannot spare much time for an interview, especially if this lasts at least an hour. A range of strategies was adopted for the recruitment of participants, with varying degrees of success for each strategy. The most successful strategy was targeting schools and negotiating access with their headmasters. Attending parent-teacher evenings proved to be a very important tactic in recruiting parents for the research. I also made use of leaflets and posters which were posted in churches, cafes, bookshops and other shops in Manchester, although the response was lower compared with the schools. A quite successful method of recruiting interviewees was through a network of contacts my partner and I developed as new parents. By contrast, the 'snowballing' technique proved to be ineffective: once they had done their interview, parents' cooperation would stop there. Another even less successful strategy consisted of posting adverts on the web; I accessed the websites of Families Online, i-Village, UK Parents and BBC Parenting, but contacts through the web brought no additional participants.

3.4 A total of sixty people thus took part in the research (out of which twenty-eight where fathers) and most of the couples (twenty-eight) were interviewed jointly. Confidentiality was assured and all the names used in this article are pseudonymous. The face to face interviews were conducted mostly in participants' homes and each lasted between 1 and $11 / 2$ hours. The interviews were semi-structured, which means that I had topics to discuss with participants. These covered four broad areas: 1) family life, 2) daily interaction with children, 3) work-life concerns and 4) work characteristics. During the interviews I also elicited accounts on topics revealing the emotional or symbolic attachments of participants, like: life with children, arrangements around mealtimes, arrangements for week-ends and most valued time in a typical day. Questions around work life were more structured than the others and covered topics from detailed job description to the degree of autonomy and job gratification.

3.5 As the research was based on semi-structured interviews, I did not systematically gather information about formal and informal support for families (e.g. help from cleaners and grandparents), or on what happens in special circumstances like children's illness. As it is clear from recent research, dual-earner parents, especially from the middle-classes, utilise these sorts of strategies to ease the conflict between work and family life (Lyonette et al. 2007; Secret, 2006). However, in this article I do not claim that symbolic factors are the only key for understanding parents' practices and strategies. On the contrary, external contingencies (such as formal and informal support for families) are seen as constituent parts of parents' mediating position and so the analysis is centred on what parents do with the time they 'buy' when they manage to get in extra help.

3.6 The sample of research participants is chiefly composed of middle-class and professional people: there are many teachers, some nurses, social and welfare workers, some other professionals like GPs, consultants, professors, a few senior managers, scientists, a company director and the dean of a university faculty. The reason why I interviewed mainly middle-class people is linked to the area where the research was carried out. South Manchester, particularly Chorlton, can be considered an area of urban gentrification (Savage et al., 2001: 879; Kidd, 2002), inhabited largely by the middle classes. South Manchester was chosen for two reasons. Firstly, it was a time- and money-saving strategy to find participants in areas near my research-base. Secondly, I wanted to maintain homogeneity of class within the small sample upon which the research was to be based; once I had recruited the first few middle-class couples, I wanted to maintain that homogeneity and I choose to keep sampling the same areas of South Manchester for similar families. An obvious implication for the type of data and the type of generalisations that can be drawn is that the study can address only middle-class practices; so when I talk about family life or work-family boundaries I refer to middle-class family narratives and middle-class work-family boundaries.

3.7 Methods of data analysis were geared to the strategy of coding and the discovery of coding paradigms (Strauss and Corbin, 1994), so that these would assist the researcher in identifying relationships among interviews' stories and themes. Thus, when no new information emerged during the interviews and when no new properties, dimensions, conditions or consequences were added to themes and stories so far collected and analysed, I then considered that the sample had reached 'theoretical saturation' (Strauss and Corbin, 1998: 212). 


\section{Meaning of different spheres: 'focus' and 'mind set'}

4.1 Parents tend to distinguish narratives of family and work into different configurations of meanings. Participants to this research mediate with external circumstances their boundaries of space and time for work and for family. Because of this I talk about their 'mediating position'. Most of the participants give accounts referring to activities oriented to create a border between their work tasks and their life at home, even when these may happen in the same physical space, like when they take work home. Here, Ross (children's guardian, Family Court), married with Kristin and father of two, speaks about his work-family balance.

Ross: I rarely work beyond 6 and sometimes I have to bring some work home, not very often, occasionally at the weekend, generally I'm home by 6 or 6.30 and I just can forget about it and I do forget about it and I think I've got quite good over the years... at sort of leaving work behind and then concentrating on the family, so it tends not to interfere with... family life which is for me a huge... a huge positive, really. (My emphasis)

4.2 Generally the majority of participants to this research refer to the spatial and physical separation of the workplace as a sign of two different areas of meaning. However from this account it is also possible to see that Ross trained himself to create a rigid boundary between work and family, carved out time and space to dedicate to the latter and so transforming the home sphere into a densely meaningful space ('huge positive'). Even participants working at home devise strategies that minimise the overlap of work task into family time. For instance: Arian, a tax writer who works full-time at home, is married and a mother of two, makes the point that she does not work at all in the evening or when the children are at home:

Interviewer: Do you ever work in the evenings?

Arian: No... Very occasionally, I mean I always get my work done; I always get my work done during the day so, I try not to do any household chores when I am with the children because they are in the nursery full-time, and it would make our time together quite stressful. (My emphasis)

4.3 While here she refers to household chores, the same approach of negotiating boundaries between work and family time happens with her paid work activity. The final outcome of such management is a relatively neat separation of the different spheres of her work and familial life, similar to that of other participants who in fact do not work at home. Caroline is a part-time product manager for an academic publisher company, has two children, is married and works at home. Her account is similar:

Interviewer: Did it used to happen to bring work home?

Caroline: When we moved to Manchester I started to work from home and then it was quite difficult to leave it sometimes... I did a lot on line and... differently I had to turn the computer off and say, like: I am not going to do it anymore, so I kind of stopped doing it in the evenings. Physically sometimes I have to attend conferences overnight or meetings and I will be away, so, I would go through it the night before...

4.4 Through her story it is possible to detect the type of trajectory participants go through when working at home, or taking work home, and dealing with issues of work and family. It becomes a careful and engaging activity oriented to the negotiation of different material and symbolic spaces in which to dedicate oneself to qualitatively different tasks, where it is possible to engage with tasks and performances otherwise not immediately compatible. This observation is consistent with the findings presented by Brannen (2005) about 'time markers' and strategies of marking, whereby couples are engaged in managing boundaries around times and spaces dedicated to different activities.

4.5 The symbolic relevance of the home and work spaces and times is also shown by a number of mechanisms reported by many participants: the 'focus' (or 'mind set') they maintain for particular areas of daily life and the 'switching off ${ }^{[2]}$ from one area of life to another. These mechanisms indicate elements of these two areas of life that are not compatible, tasks that are not possible to do simultaneously and so indicate different spheres of meanings.

Horace (Arian's husband): (...) did you find you worked harder when you were in the office?

Arian: when I was in the office... there are times when you don't do anything, time when you just switch off mentally, 'cause when you use your brain for work... it's hard to concentrate all day... so now I can switch off and do something completely different, whereas in the office you still have to sit down there and pretend you're doing something, don't you (laughs) (My 
emphasis)

4.6 Working from home, Arian switches herself between different symbolic spheres as people working from their workplace move physically from that place to home. In the next account, Mary (consultant, part-time) and Alex (director of a small software firm, full-time), parents of two, refer to a similar mechanism which has the symbolic consequences of re-drawing the boundaries between home matters and work matters, and to an extent between the home self and the work self.

Interviewer: What about bringing work home?

Alex: I try to, but it doesn't work... there is too much other stuff to do, like Dorian and Geoff (their sons), by the time you've finished sorting them out you're past it, your mind has moved on, you haven't got the focus, or the energy actually to any work at home anymore, which is a good thing, I think.

Mary: You've turned off your work brain and you can't be bothered... and also, I don't know about you, but l've learnt... you give only a certain amount of time to work, but you are much more productive when you are there, 'cause you have to be. But you don't have lunch... (My emphasis)

4.7 This couple talk about energy which, with time, is a well known factor in the study of work-family boundaries, but they also talk about losing 'focus' when moving from one set of practices to another (children and paid work). The presence of a focus for each set of practices is here interpreted as the (social rather than psychological) tendency of participants to give a precise meaning to daily events, in that they have one focus or mindset for family and another for work. The 'turning off' of the 'work brain' indicates symbolic elements in the understanding of home and work interface.

4.8 Thus parents devise systems of symbolic references when dealing with family and work, that is: there are meanings of family and work that are highly symbolic for them. These meanings are linked to the type of emotional and material attachments working parents invest in these domains of life (Hochschild, 1997). The structures around work engagements and family care are essential for working parents and with these, the finite resources of 'time' and 'energy' that they have to devote to both domains. However, the emphasis on parameters such as time and energy cannot conceal the crucial importance of the symbolic significance that these domains come to assume for working parents: employment structure and family life assume such importance for working parents because they are containers of meaning - containers of symbolic and emotional relations (Thompson and Bunderson, 2001).

4.9 Dual-earner parents deal with time at work, which is structured along labour market principles (time in exchange for money), but also deal with caring, with 'quality' and 'family' time, which in principle ought not to be measured. Obviously there are contradictions and disjunctions happening between these two conceptions of time, which reflect how the boundaries between work and family are left to the 'choice' of individuals. So the work-family conflict tends to assume an inward meaning, as families are left to cope 'without any institutional or group mechanisms to defray or diffuse' (Brannen: 2005: 118) these contradictions. This inward meaning may be taken as a sign that the standard structure articulated around the differentiation of workplace and home (Richardson, 2006) does not readily give a differentiation of meaning any longer and that parents have to negotiate privately the boundaries of work and family, having to rely in different resources from their public and private spheres.

4.10 In many studies (e.g. Montgomery et al., 2005; Perlow, 1998), the boundaries between work and home are seen as eroded by new management practices, technological advances in communication and different family arrangements, so that it is possible to speak about 'blurred' boundaries between the two. However, this article offers a more nuanced explanation suggesting that the articulation of work and family is such that the symbolic markers delineating these two spheres are ever less 'social' (see also Brannen, 2005). Along this reasoning, the present analysis of work-family boundaries suggests that these two spheres should not be considered as undifferentiated, as parents are in the process of redrawing and reworking these boundaries, to negotiate their meanings vis-à-vis changing employment conditions. These observations find a resonance in the recent research of Wajcman et al. (2008) where the use of mobile phone is seen as a tool for the micro-coordination of private and work matters for busy parents, rather than an ominous technological means that simply blur the boundary between home and work.

4.11 This section analysed the 'focus' that parents maintain on work and non-work, but to what extent are these middle-class parents free to negotiate the boundary between work and family?

\section{Mediating positions and external structures}

5.1 The approaches to work and family life analysed in the previous section indicate the mediating positions 
of participants in the internal arrangements of the two sets of activities. These approaches are oriented to re-shape the distinctions between home life on one hand and paid work on the other; so this data seems to suggest that there is an element of choice in establishing the work-family boundary, which it is worth analysing further. There are couples who reported to have made 'a conscientious decision that we'd rather spend time with the children [so] they don't have to go into the after-school club every night' than work long hours. For instance, Josh works about 35 hours a week for his cousins' engineering company, having once worked far longer hours in the transport sector ('I used to work 50 hours a week'), his wife Claudia is parttime lecturer of English as Foreign Language and they have two children. However these choices depend from the flexibility of their economic circumstances: indeed they both reported having fairly flexible jobs in terms of the possibility of arranging working hours to suit their domestic needs, and crucially Claudia is also part-time. The majority of the women participants work part-time and this arrangement can be described as the 'one and half breadwinners household model': the work-family articulation is arranged through a combination of traditional normative assumptions relating to gendered responsibilities for care work and the indifference of work organisations to the lives of people entering the labour market (Crompton, 2006). Through that, the outcome of this couple's arrangements with work is a better 'quality of life' (Claudia) for themselves and their family:

Josh: If Claudia has a lecture and one of the children is ill, she has to go to work, because she's timetabled, so there is people expecting her... with my job, 'cause I work for a family company, if I take a child to a doctor, I just ring up and say I can't be there until 11 or 12 o'clock, because I'm doing such and such... and then Claudia will come at 1.00 o'clock, take over. It's so flexible!

5.2 The use of flexibility in these cases is thus geared to the 'protection' of the home sphere (Hill et al., 2008). Through gender lines this couple harmonise work and family, keeping clear boundaries between the two domains. In my sample, usually the female partner takes up a part-time job so to dedicate herself to family related matters such as housework and caring for the children, in order to arrange the quality time that family spends together. Through this household model a symbolic space for the family is created. It is then a gendered structure that still influences the way couples try to give a meaning to the work and family articulation (Gatrell, 2005; Lewis, 2001; Rossi, 2006).

5.3 Work and family belong to critically distinct sets of meanings; that is, they refer to a meaningful order of daily life, tightly connected with a gender order and with employment circumstances. Indeed, in Caroline's (whom we met before) accounts we can see how considerations of work-family boundaries more clearly range from issues of meaning to issues of work conditions:

Interviewer: Did you find difficult with one child to combine work and family life?

Caroline: It's like a different life; I also had to learn... I was starting something new and different in the whole way of doing everything, I think that was difficult to do... it's just so busy with the day-to-day survival... I just think 'I made it through another day and I've not killed them', you know! So the whole focus shifts a bit. (My emphasis)

5.4 In her case, the room for managing the boundaries between family, personal life and paid work is surely more restricted than that enjoyed by other participants. Such a difference is partially explained by the fact that Caroline works part-time, like Claudia, but her degree of self management is minor, she also works in the marketing sector and she has to put up with the 'pressure to perform and get your sales'. Thus, the conditions of her job are influential in the way she focuses on work and familial practices (Lyonette et al., 2007). How much, then, does the content and the conditions of their jobs have to do with their activities oriented to the shaping of spheres of daily life?

5.5 In order to understand the articulation of work and family it is important to consider these spheres not as 'black boxes' (Hochschild, 1997), to analyse their internal dynamics and so to unpack the details and the specific issues that make up more general trends. With this article, I consider work and family as areas of symbolic meaning for working parents. These symbolic areas change form according to a series of factors, related to the internal dynamics of work and home, to 'meaning making' of working parents and to the structures where they are involved. As the interplay between structures and meaning is considered crucial in understanding the work-family articulation, this analysis focuses not only on work conditions, but also on the content of participants' jobs and their experience of it.

5.6 The content of participants' job results very important in providing the frame for the boundary management of the two domains. Work can change parents' perception of the sense of self, and with that the symbolic configuration of the private and public spheres, as it is possible to see in the next accounts from Denise (welfare rights service manager) and Jeffrey (professor), parents of two. 
Denise: yeah, because when I haven't had a job... We've spent a year in America, it has been fantastic, but I just was looking after kids of three and five... my status was suddenly just 'wife'. I didn't like that. I need a balance. I had to go back to work part-time when they were quite young because I found it too much being a full-time mum.

Jeffrey: For my self esteem? Yes. It's my whole identity ehmm completely, it's the whole... Research is everything that is important to me... (My emphasis)

5.7 It is clear from their accounts that their paid work represents a meaningful part of their activities and therefore it can be considered a factor conditioning their 'identity' (or their 'focus', as other participants refer to) and how this is placed in the context of family-work narratives. Considering work as a material as well as a symbolic structure helps to understand what kind of 'balance' parents want to give to the work family articulation. There is an identity which is implied in the work they do which also influence the focus on work and family time, but in a dialectical tension with other structures like 1) gender and 2) occupational position.

1. From the above account, it transpires that, even if both partners tend to present a common narrative, men's concern is over the sources of identity and often their hierarchical importance, whereas women recognise the value of these sets of practices and their 'balance', reflecting how the boundaries between family and work are still a gendered concern (Gatrell, 2005; Wajcman and Martin, 2002).

2. The experience of work and the self esteem which participants derive from their work, is tightly intertwined with their level of seniority in the workplace and so, to an extent, with their occupational class. Thus the ambivalence of work as an external constraint on their private domain and work as a source of self-esteem differs according to different socio-economic positions. The following account relates work autonomy to the subjective meanings of work, both essential factors for developing an emotional base for reconciling work life with home life. In the next account, Konrad (Publications Manager) and Monica (Genetic Counsellor and Researcher), married and parents of two, talk about their job gratification:

Konrad: Well part of it is the autonomy... I have a lot of control over what I do... the fact that I can be flexible if need be, and it can be very interesting and there are often new areas that you need to become knowledgeable about, that's interesting.

Monica: Many of the same sort of things, I like working autonomously... I like the intellectual challenge of what I do in both jobs... in my clinical job I enjoy the fact that I am helping people and in my research job I suppose I get a lot of satisfaction out of getting work published... I enjoy having a high profile in my profession... I enjoy the status of my work (My emphasis)

5.8 The degree to which the job is perceived as meaningful can be linked to the degree of autonomy and this link is part of a more general connection between occupational class and type of symbolic boundary adopted. In general, participants with 'high job resources' (measured as the degree of control over work tasks) are those who experience positively the influence from work (Demerouti and Geurts, 2004, White et al., 2003). More in particular, my study finds that aspects of the job which entail becoming knowledgeable about 'interesting' things are aspects that participants value in themselves as people, as well as workers: the personal interest in developing these skills is not determined by organisational goals, but rather it is matched by their work life. In that sense, this work narrative represents the symbolic resource used to reconcile the family and work spheres: it represents a symbolic connection of emotional areas of daily life.

5.9 Nonetheless there is a limit to which the middle-class sample of this research can enjoy autonomy and flexibility in managing the boundary of work and family. Norman is a software engineer/project manager who works at home, married and father of one. He points at these structures under the form of the 'pressure' that clients put on him. The following account shows that if there is a mediating activity on the part of the subjects, the division of spheres of meaning is also shaped by external factors:

Norman: (...) there's been other pressures and they were looking to outsource... some work to India, so I had to basically I had to step up the work level so that they thought, 'oh, we can't do that because Norman is so brilliant.' If I did nothing for a month, before I knew it they could have quite easily outsourced my job to India so I put more effort in, didn't get paid any more, but... just to keep them happy. (My emphasis)

5.10 From these accounts it is possible to conclude that participants manage the boundary between work and family connecting the meaning of these spheres to the work structure in its valence as resource and as constraint. The focus on the 'symbolic' highlights how work and household structures are not only 
constraints or resources for parents, but these tend to assume an additional meaning which they emphatically invest in their life and their sense of self. Differentiated thorough gender and degree of seniority, parents are emotionally linked to these spheres of life and try articulate work and family according to the symbolic relevance of these, relevance that is inextricably linked to external structures. In that sense, this study proposes a broader conceptualisation of the work-family articulation, which is relatively new (Demerouti and Geurts, 2004) and which is particularly suited to explore the interplay between symbolic elements and structural constraints, between social interaction and wider social codes.

5.11 In these two sections we have seen how participants mediate symbolic spaces for family and work; but if a form of boundary between the two spheres is achieved through participants' mediating activity and meanings, such activities and meanings are to be considered adaptive to (externally) given conditions, as well as active and voluntary. This may appear a logical contradiction, but this contradiction expresses how middle-class couples' mediating activities may be just an attempt to make sense of situations that are beyond their control. Notably, this contradiction signals that the relation of meaning and structure in the work and family interface needs to be understood in a symbolic frame, whereby social and economic constraints become parameters informing parents' sense of self and the meanings of their domains of life. I also argue that this position captures the dialectic between the mediating position of subjects and their external 'contingencies' (Edgar 2004), so exposing the complexities of home and work situations.

\section{Conclusions}

6.1 The findings analysed in this article show how working parents use a series of resources, both symbolic and emotional, or even work resources, when mediating the demands of-and giving meanings to-family and work. Parents are involved in 'symbolic boundary management' of work and family, as they tend to give an orderly flow of events to their daily lives. In this article then, the 'symbolic dimension' refers to participants' meanings enabling the transformation of daily practices into values close or distant to private resources. In particular, I have shown how participants manage the work-family boundary according to their symbolic attachments or even to their sense of self, but I also explored how employment conditions and the specific content of participants' jobs inform their 'focus' on work and family and equally shape these boundaries. This particular articulation of subjective meanings and work structure approaches the work and family interface from an angle which is often neglected.

6.2 Thus, I argue that the boundary between work and family is re-shaped by parents according to the meaning they attach to daily sets of activities, making it difficult to express the relation of work and family purely in chronometric terms. Yet they do so being entangled in employment structures that set precise constraints, but also offer, in a way that is differentiated through gender and occupational class, symbolic resources. Here then the analysis of the work-family interface takes in account the job content of parents and their job resources, an approach deemed to be crucial by some studies (Dex, 2003), but rarely carried out in work-family research.

6.3 The one and half breadwinners' household model (Crompton, 2006) is equally essential in understanding how parents manage the work-family articulation and is linked to parents' asymmetric job resources. Through the part-time employment of most of female participants, gender inequality is reproduced in practical terms, in the division of household tasks, and in symbolic terms, in attributing meanings that consubstantiates the image of mothers as workers and parents in sequential time, so making the difficulties of managing the boundaries of work and family especially acute for mothers (Hochschild, 2003; Wajcman and Martin, 2002). Middle-class families participated to this research, yet their accounts point at different connections between seniority (and job's 'status') and the type of level of work-family conflict. A medium-high level of autonomy at work, and so medium-high resources in the job, is connected to an experience of work-family integration, rather than purely conflict and vice versa (White et al., 2003), although, even for the middle-class participants to this research, the threat of industrial restructuring is often present, so eroding effectively the spaces of their autonomy.

6.4 On a more theoretical level, this approach takes a step back from considering family and work as reified entities: here the analysis opens up the domains of work and family taking into consideration participants' experience and showing the personal and social relations that make up patterns of action. Indeed, only through such an approach could considerations on the symbolic side of the work-family boundaries have emerged, and with them, issues concerning the meaningful order of daily life, which are vital to understanding the emotional attachments of participants to these domains and which are rarely analysed in other studies. On this point, I argue that mechanistic approaches like those of Vander Lippe (2007), Voydanoff (2001), or Greenhaus (1989) cannot explore these issues as deeply. This article then adds a voice to those who call for the understanding of the 'contexts' of the work-family conflict, where these contexts are likely to be explored through qualitative, as well as quantitative, research (Lyonette et al., 2007). 
6.5 Hence, in this article the 'problem' of reconciling the often contrasting demands of home and work is treated not only as a practical concern, but also as a peculiar arena where emotions, loyalties and responsibilities are at time converging, at time diverging. Thus, the so-called 'work-family balance' is considered to be an area which is more than the sum of time and energy devoted to these domains, it is an area which includes different conceptions of time. Consequently this redrawing of the boundaries between work and family poses problems for a broad policy intervention, although on the basis of this study it is important to take into consideration that part-time paid employment for women is vital for the construction of the symbolic space of home, but reconfigures in traditional terms the position of mothers in the domestic sphere and in the labour market.

6.6 Examining the internal dynamics of work and family, as well as exposing a totality of factors implied in the work-family boundaries (i.e. not only 'time' and 'energy'), brings to light the tension between participants' symbolic activities and their external constraints. This tension indicates the lack of social mediation between work and familial practices. On that my research converges with others (Brannen, 2005; Hochschild, 2003) in observing that the configuration of work and family is to an extent 'privatised' (Gambles et al., 2006): working parents think that it is their responsibility to combine work and family life. In other words, this research has found that there is a sort of 'dumping' of practical problems arising from daily efforts to combine work and family engagements directly onto individuals. This, unsurprisingly in the age of flexible capitalism, places 'the costs of adapting to social change on people instead of employers' (Edgar, 2004).

\section{Notes}

${ }^{1}$ Here I also follow the Italian phenomenological tradition, where the term symbolic can be equated to culture, but it has a more general meaning; it not only indicates codified forms of expression and communication, it also points at the process of constitution of these forms of expression and communication through the continuous elaboration that the agency involved in this process develops in relation with culture (Crespi, 1986: 43).

2 The 'switching technique' is for Felstead and Jewson a technology of the self peculiar to home-workers in that it implies 'switching between the temporalities and localities of employment and domestic relationships' (2000: 127), however here the switching mechanism is though to be a more general relation between participants and their relations with home and work.

\section{References}

BAILYN, L. (1993) Breaking the mould: women, men and time in the new corporate world . New York: Macmillan.

BERG, P., KALLEBERG, A.L. and APPELBAUM, E. (2003) 'Balancing work and family: the role of high commitment environments', Industrial relations, Vol. 42, No. 2, pp. 168-187. [doi:10.1111/1468-232X00286]

BRANNEN, J. (2005) 'Time and the negotiation of work-family boundaries: autonomy or illusion?', Time \& Society, Vol. 14, No. 1, pp. 113-131. [doi:10.1177/0961463X05050299]

BRANNEN, J., NILSEN, A., LEWIS, S. and SMITHSON, J. (editors) (2002) Young Europeans, work and family life: futures in transition. London: Routledge.

BRUNKHORST, H. (1996) 'Critical theory and empirical research', in Rasmussen, D. (editor) The handbook of critical theory. Oxford: Blackwell.

CAMPBELL-CLARK, S. (2000) 'Work/family border theory: a new theory of work/family balance', Human relations, Vol. 53, No. 6, pp. 747-770. [doi:10.1177/0018726700536001]

CRESPI, F. (1986) Le vie della sociologia. Bologna: II Mulino.

CROMPTON, R. (2006) Employment and the family. Cambridge: Cambridge University Press. [doi:10.1017/CBO9780511488962]

DEMEROUTI, E. and GEURTS, S. (2004) 'Towards a typology of work-home interaction', Community, Work and Family, Vol. 7, No. 3, pp. 285-309. [doi:10.1080/1366880042000295727]

DEX, S. (2003) Families and work in the twenty-first century. Bristol: The Policy Press, Joseph Rowntree Foundation. 
DONATI, P. and PRANDINI, R. (2007) 'The family in the light of a new relational theory of primary, secondary and generalised social capital', International Review of Sociology, Vol. 17, No. 2, pp. 209-223. [doi:10.1080/03906700701356812]

EDGAR, D. (2004) 'Globalisation and Western bias in family sociology', in Scott, J. Treas, J. and Richard, M. The Black well companion to the sociology of families . Oxford: Blackwell.

[doi:10.1002/9780470999004.ch1]

FELSTEAD, A. and JEWSON, N. (2000) In work at home, towards an understanding of homeworking . London: Routledge.

GAMBLES, R., LEWIS, S. and RAPOPORT, R. (2006) The myth of work-life balance. Chichester: J. Wiley and Sons Ltd. [doi:10.1002/9780470713266]

GATRELL, C. (2005) Hard labour. Maidenhead: Oxford University Press.

GOLDSMITH, E. B. (editor) (1989) Work and family. California: Sage.

GOTTLIEB, B.H., KELLOWAY, E.K. and BARHAM, E. (1998) Flexible work arrangements - managing the work-family boundary. Chichester: J. Wiley and Sons Ltd.

GREENHAUS, J.H. (1989) 'The intersection of work and family roles', in Goldsmith, E.B. (editor) Work and family: theory, research, applications. Newbury Park, Ca: Sage.

GUSFIELD, J.R. and MICHALOWICZ, J. (1984) 'Secular symbolism: studies of ritual, ceremony and the symbolic order in modern life', Annual review of sociology , Vol. 10, No. 3, pp. 311-342.

HALPERN, D.F. and MURPHY, S.E. (editors) (2005) From work-family balance to work-family interaction . Mahwah, New Jersey: Lawrence Erlbaum Associates.

HILL, J., JACOB, J., SHANNON, L., BRENNAN, R., BLANCHARD, and V., MARTINENGO, G. (2008) 'Exploring the relationship of workplace flexibility, gender, and life stage to family-to-work conflict, and stress and burnout', Community, Work \& Family, Vol. 11, No. 2, pp. 165-181.

HOCHSCHILD, A.R. (1996) 'The emotional geography of work and family life' in Morris L. and Lyon, E.S. (editors) Gender relations in private and public . Basingstoke: Macmillan.

HOCHSCHILD, A.R. (1997) The Time Bind. New York: Henry Holt Co.

HOCHSCHILD, A.R. (2003) The commercialisation of intimate life. Berkeley: University of California Press.

KIDD, A. (2002) Manchester: a history. Edinburgh: Edinburgh University Press

LEWIS, S. (2001) 'Restructuring workplace cultures: the ultimate work-family challenge?', Women in management review, Vol. 16, No. 1, pp. 3-24. [doi:10.1108/09649420110380256]

LEWIS, S. (2003) 'The integration of paid work and the rest of life. Is post-industrial work the new leisure?', Leisure Studies, Vol. 22, No. 4, pp. 343-355. [doi:10.1080/02614360310001594131]

LEWIS, S., BRANNEN, J. and NILSEN, A. (editors) (2009) Work, families and organisations in transition: European Perspectives. London: Policy Press.

LEWIS, S. and COOPER, C.L. (2005) Work-life integration: case studies in organisational change. Chichester: John Wiley and Sons Ltd.

LEWIS, S., GUERREIRO, M.D. and BRANNEN, J. (2006) 'Case studies in work-family research', in PittCatsouphes, M. Kossek, E. and Sweet, S. Work and family handbook. Mahwah, New Jersey: Lawrence Erlbaum Associates, Inc.

LYONETTE, C., CROMPTON, R. and WALL, K. (2007) 'Gender, occupational class and work-life conflict', Community, Work and Family, Vol. 10, No. 3, pp. 283-308. [doi:10.1080/13668800701456245]

MONTGOMERY, A.J., PANAGOPOULOU, E.P., PEETERS, M.C. and SCHAUFELI, W.B. (2005) 'The meaning of work and home', Community, Work and Family, Vol. 8, No. 2, pp. 189-317.

[doi:10.1080/13668800500049605]

MORGAN, D. (1996) Family Connections. Cambridge: Polity Press. 
NIPPERT-ENG, C. (1996) Home and work: negotiating boundaries through everyday life. Chicago: University of Chicago Press.

PEPER, B., Van DOORNE, A. and Den DULK, L. (editors) (2005) Flexible working and organisational change: the integration of work and personal life. Cheltenham: Edward Elgar.

PERLOW, L.A. (1998) 'Boundary control: the social ordering of work and family time in a high tech organisation', Administrative science quarterly, Vol. 43, No. 2. [doi:10.2307/2393855]

PIOTRKOWSKI, C. (1978) Work and the family system. New York: Free Press.

RICHARDSON, P. (2006) 'Anthropology of the workplace and the family', in Pitt-Catsouphes, M. Kossek, E. and Sweet, S. Work and family handbook. Mahwah, New Jersey: Lawrence Erlbaum Associates, Inc.

ROSSI, G. (2006) 'Work and family between idealism and reality' in Rossi, G. (editor) Reconciling work and family. Milano: Franco Angeli.

SAVAGE, M. BAGNALL, G. and LONGHURST, B. (2001) 'Ordinary, ambivalent and defensive: class identities in the Northwest of England', Sociology, Vol. 35, No. 4, pp. 870-92.

SECRET, M. (2006) 'Integrating paid work and family work', Community, Work and Family, Vol. 9, No. 4, pp. 357-371. [doi:10.1080/13668800600925027]

SMART, C. (2007) Personal life. Cambridge: Polity.

STRAUSS, A. and CORBIN, J. (1994) 'Grounded theory methodology: an overview', in Denzin, N.K. (editor) Handbook of qualitative research. London: Sage.

STRAUSS, A. and CORBIN, J. (1998) Basics of qualitative research: grounded theory procedure and techniques. Chicago: Aldine.

THOMPSON, J. and BUNDERSON, S. (2001) 'Work / non-work conflict and the phenomenology of time', Work and Occupations, Vol. 28, No. 1, pp. 17-39. [doi:10.1177/0730888401028001003]

VANDER LIPPE, T. (2007) 'Dutch workers and time pressure: household and workplace characteristics', Work, Employment and Society, Vol. 21, No. 4, pp. 693-711. [doi:10.1177/0950017007082877]

VOYDANOFF, P. (1987) Work and family life. London: Sage.

VOYDANOFF, P. (2001) 'Conceptualising community in the context of work and family', Community, Work and Family, Vol. 4, No. 2, pp. 221-242. [doi:10.1080/13668800120061125]

WAJCMAN, J. and MARTIN, B. (2002) 'Narratives of identity in modern management', Sociology, Vol. 36, No. 4, pp. 985-1002. [doi:10.1177/003803850203600410]

WAJCMAN, J., BITTMAN, M. and BROWN, J. (2008) 'Families without borders: mobile phones, connectedness and work-home divisions', Sociology, Vol. 42, No. 4, pp. 635-652.

[doi:10.1177/0038038508091620]

WHITE, M., HILL, S., McGOVERN, P., MILLS, C. and SMEATON, D. (2003) 'High performance management practices, working hours and work-life balance', British journal of industrial relations, Vol. 41, No. 2, pp. 175-195. [doi:10.1111/1467-8543.00268] 